\title{
State of the art in chromovitrectomy
}

\author{
Estado da arte da cromovitrectomia
}

Rafael Ramos Caiado', Milton Nunes de Moraes-Filho', André Maia', Eduardo Büchelle Rodrigues', Michel Eid Farah', Maurício Maia ${ }^{1}$

\begin{abstract}
Vitrectomy is a surgery that involves complex and delicate techniques that treat diseases such as macular hole, epiretinal membrane and diabetic macular edema. Chromovitrectomy is one of these techniques and includes the use of coloring agents such as vital dyes or crystals to enhanced visibility of transparent structures during vitrectomy. The aim of this study was to present a modern approach, based on scientific evidence, about the application and indication of vital coloring agents during vitrectomy. The use of such agents has made this surgery more predictable and has increased its post-operative prognosis. Although research on chromovitrectomy is currently expanding there is still not an established gold standard dyeing agent.
\end{abstract}

Keywords: Vitrectomy; Vitreous body; Macular hole; Retina; Dyeing agents; Epiretinal membrane

\section{$\underline{\text { RESUMO }}$}

A cirurgia vitreorretiniana é uma cirurgia que envolve técnicas complexas e delicadas que tratam doenças como buraco macular, membrana epirretiniana e o edema macular diabético. A cromovitrectomia é uma dessas técnicas que incluem o uso de corantes compostos de pigmentos vitais ou cristais para melhorar a visibilização de estruturas transparentes durante a cirurgia de vitrectomia. O objetivo desse artigo foi apresentar uma abordagem atual, baseada em evidências, sobre a aplicação e indicação de corantes vitais durante a cirurgia vitreorretiniana. $\mathrm{O}$ emprego desses corantes possibilitou uma maior previsibilidade para a cirurgia, melhorando assim seu prognóstico pós-operatório. Apesar do campo da cromovitrectomia está em plena expansão de pesquisas, um corante gold standard para cromovitrectomia ainda não está estabelecido.

Descritores: Vitrectomia; Corpo vítreo; Buracos maculares; Retina; Agentes corantes; Membrana epirretiniana

\footnotetext{
Universidade Federal de São Paulo, São Paulo (SP), Brasil;

Interesse de propriedade: Dr. Eduardo B. Rodrigues têm a patente do VINCE em conjunto com a Dutch Ophthalmics, Holanda

Trabalho realizado pelo Departamento de Oftalmologia da Universidade Federal de São Paulo São Paulo (SP), Brasil
}

The authors declare no conflicts of interest

Recebido para publicação em 7/11/2013 - Aceito para publicação em 14/9/2014 


\section{INTRODUCTION}

${ }^{66} \mathrm{C}$ hromovitrectomy" is the intraocular application of dyes to assist visualization of pre-retinal tissues during vitreoretinal surgery. It has been introduced with the goal of avoiding ocular complications related to internal limiting membrane (ILM) peeling, poor removal of the vitreous, and incomplete removal of the epiretinal membrane (ERM). Thereby leading to improvement in the postoperative visual acuity. Since 2000, chromovitrectomy has become a popular approach among vitreoretinal specialists ${ }^{(1-3)}$. The first vital dye used in chromovitrectomy, indocyanine green (ICG), facilitated the identification of the fine and transparent ILM. Following ICG, trypan blue (TB) has been introduced as an appropriate agent to identify the several (ERM), and triamcinolone acetonide (TA) has been found to stain the vitreous well. Recently, additional vital dyes such as infracyanine green (IfCG) and patent blue (PB) have been proposed for intraocular application during vitrectomy ${ }^{(4)}$. In this article the current knowledge involving the use of dyes in chromovitrectomy will be discussed. In order to minimize the risk of toxic effects of dyes in chromovitrectomy surgical recommendations are presented.

\section{Use of vital dyes for internal limiting membrane}

Internal limiting membrane (ILM) peeling to treat idiopathic macular holes $(\mathrm{MH})$ was first described by Eckardt et al., in 1997. A large meta-analysis of published nonrandomized studies involving 1,654 eyes suggested that ILM-maculorhexis increases anatomic and functional success rates of IMH surgery (figure 1) $)^{(5)}$. However, surgical removal of ILM may lead to retinal damage because the ILM is an intraocular structure with 10 micrometers of thickness (figure 2). The two main complications of ILM removal are visual field defects and retinal pigment epithelium (RPE) damage. Visual field defects after ILM removal mainly located temporal to the macula could be related to mechanical trauma to optic disc, to the fluid-air exchange or to direct trauma to the retina (figure 1A). Macular retinal pigmentary epithelial hyperpigmentation or hypofluorescence on angiography could be induced by surgical trauma or photo toxicity ${ }^{(4)}$. In order to try to minimize complications related to surgical trauma and to better visualization of MLI most common dyes are presented.

\subsection{Indocyanine green}

The application of intravitreal ICG was first reported in cadaveric eyes to improve the visualization of the ILM. Since then, many articles have been released regarding the use of ICG as a surgical adjuvant of the identification and removal of the ILM in macular surgery (figures 3 and 7A).

ICG adheres well to the extracellular matrix components of the ILM, such as collagen type 4 , laminin and fibronectin ${ }^{(6)}$. In a porcine model, ICG with light exposure produces a significant increase in biomechanical stiffness, thereby facilitating ILM peeling ${ }^{(7)}$. Many authors have reported easier and less traumatic ICG-guided peeling with good clinical results. Macular hole (MH) closure rate may be achieved in 74 to $100 \%$ of patients using ICG-guided ILM peeling ${ }^{(4,8)}$.

However, the potential for toxic effects of ICG on the re-

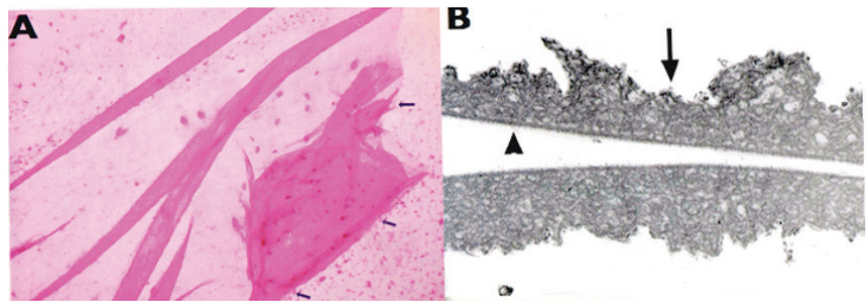

Figure 1: Histological evaluation of internal limiting membrane (ILM) from human eyes; A - Light microscopy showing the ILM (intense staining at the folds). Note that this membrane is slightly stained along the entire portion that it is not folded (arrows at the edges of the ILM); the dots - background - are the millipore filter. (Hematoxilineosin. Original magnification x 40); B - Electron Microscopy of a folded ILM (both "ILM vitreous surfaces" are almost touching); note the mild amount of cellular debris along the retinal surface - arrows. $(13.000 \mathrm{x})$

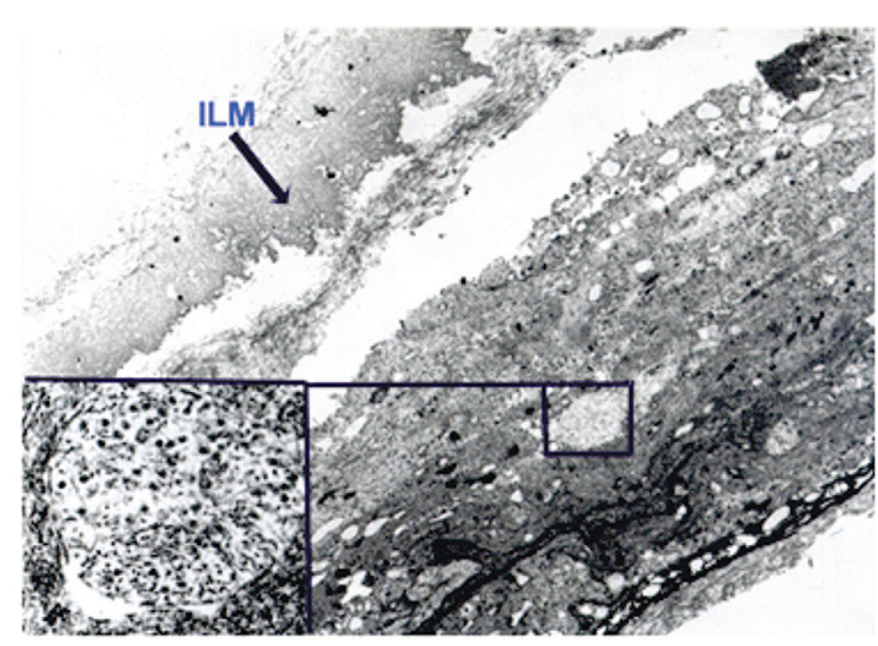

Figure 2: Electron microscopy of the ILM after peeling procedure with no use of dyes. Despites the gentle maneuver during the surgery, a portion of the nerve fiber layer/ganglion cells (inferior left) was peeled within the ILM; this results in visual fields defects by clinical evaluation

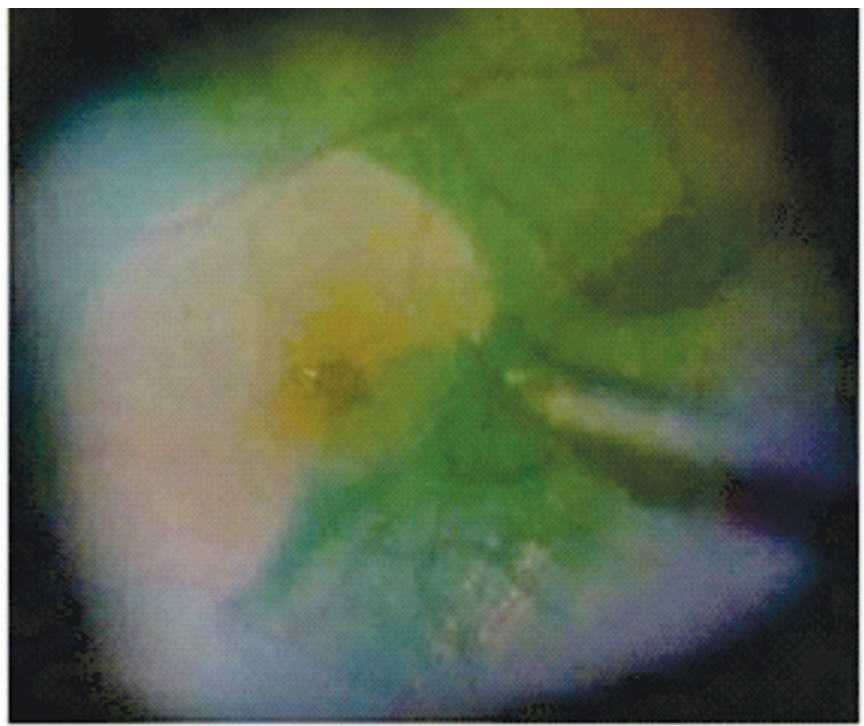

Figure 3: Peeling is facilitated because ICG produce an ILM stiffness and a very good contrast to the retina 


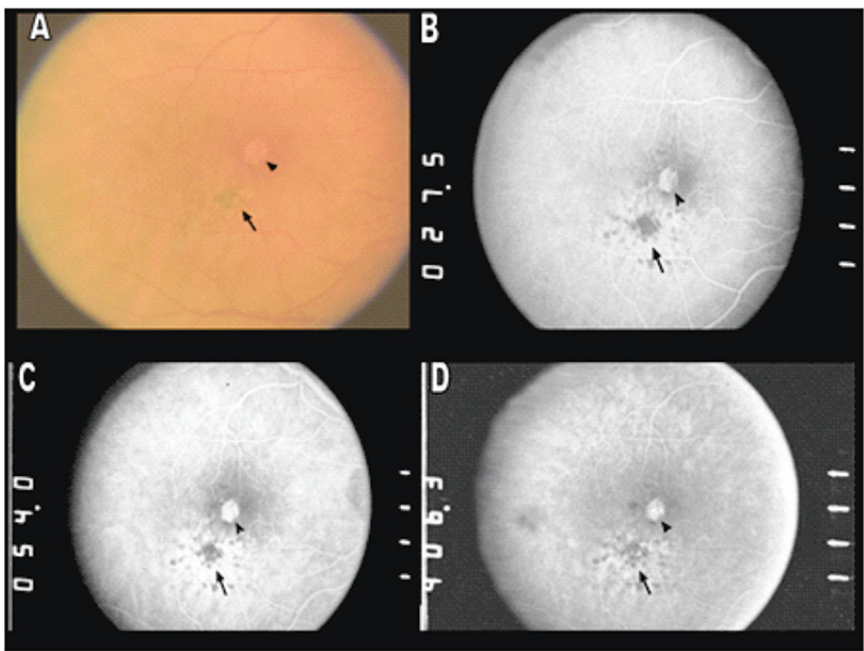

Figure 4: RPE changes after ILM peeling in macular hole surgery guided by $5 \mathrm{mg} / \mathrm{mL}$ of indocyanine green; A - Fundus photography showing that macular hole is sealed. However, pigmentary changes are observed (arrow) and abnormal clinical aspect the previous macular hole (arrowhead); B - Early phase of fluorescein angiogram showing hypofluorescent image inferior to the previous macular hole (arrow) and hyperfluorescent image at the topography of the previous macular hole position (arrowhead) due to probable window defects related to RPE atrophic changes

tina has been suggested ${ }^{(9-11)}$. ICG may persist after macular hole surgery for up to 36 months $^{(4)}$. In addition, ICG could also migrate to subretinal space through the $\mathrm{MH}$, causing retinal damage ${ }^{(12-}$ 14). Complications of ICG-assisted chromovitrectomy include RPE changes, visual field defects, and optic nerve atrophy ${ }^{(4,15)}$.

Few controlled studies have been performed to compare ILM removal with and without ICG staining in MH surgery. Some authors found significantly worse visual outcomes when ICG was used $^{(16-18)}$. The better outcomes in recent papers may be explained by a more careful ICG-injection technique ${ }^{(4,19)}$.

In comparing studies of ICG-assisted MH surgery criteria such as dye incubation time, concentration and osmolarity should be noted. Incubation time, the time that the dye remains in the vitreous cavity before aspiration, may vary from immediate removal to five minutes. RPE changes have been found mainly in studies reporting incubation time over 30 seconds. RPE toxicity is more common when the ICG solution has an osmolarity below $270 \mathrm{mOsm}$ and concentration above $0.5 \%{ }^{(4)}$.

The first use of ICG in MH surgery was with a dye concentration of $0.5 \%$. A lower concentration was thought to be safer after RPE changes and visual field defects appeared. Low ICG concentration $(0.125 \%)$ found no signs of retinal toxicity, with good anatomical and visual results ${ }^{(20)}$. In contrast, Engelbrecht et al. using the same ICG concentration observed RPE changes in $54.5 \%{ }^{(21)}$. The difference could be related to the solution osmolarity, which was $299 \mathrm{mOsm}$ in the former and $250 \mathrm{mOsm}$ in the latter. Our research team observed $27.5 \%$ of RPE abnormalities after $5 \mathrm{mg} / \mathrm{mL}$ of ICG used with osmolarity of $270 \mathrm{mOsm}$ (figure 4). This high rate of RPE abnormalities may be related to the ICG concentration, technique of application, ICG exposure to light or a combination of factors ${ }^{(9)}$. Recently studies have utilized ICG in a concentration of $0.05 \%$ and

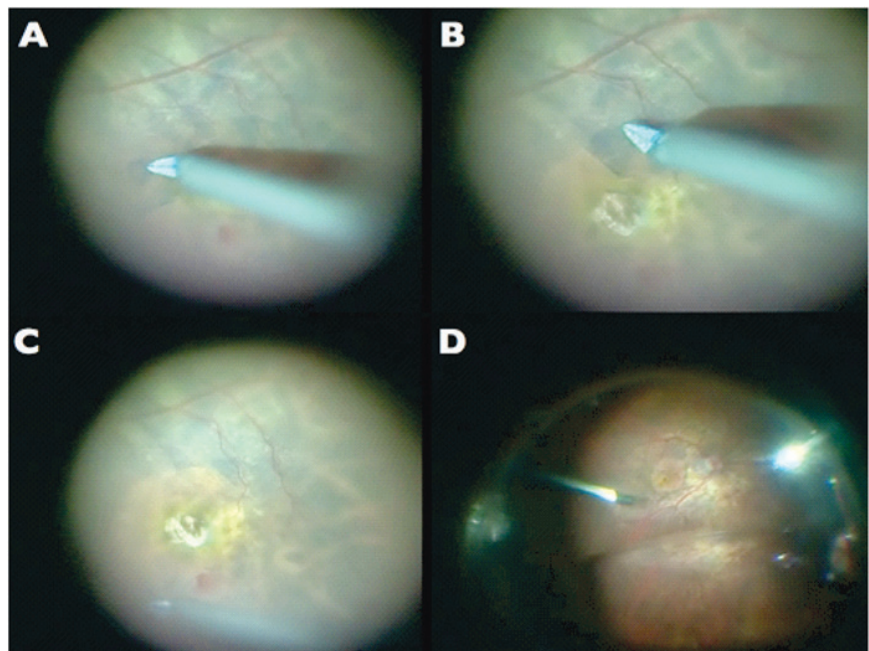

Figure 5: Intraoperative view of chronic macular hole submitted to ILM peeling guided by brilliant blue $0.5 \mathrm{mg} / \mathrm{ml}$ of brilliant blue staining - Ophthblue ${ }^{\mathrm{TM}}$ (Ophthalmos, Brazil); A - Initial step of ILM peeling grasped by intraocula forceps; $\mathrm{B}$ - Intermediate phase of maculorrhexis showing the blue ILM in contrast to the subjacent unstained retina $\mathrm{C}-$ Final aspect of ILM peeling. Note the presence of the white triamcinolone acetonide (into the macular hole) previously used for posterior hyaloid detachment; D - Fluid-air exchange. Note the air bubble inferiorly

osmolarity around 290mOsm with few or no signs of RPE toxicity $^{(4)}$.

A meta-analysis of ICG application for ILM-peeling in 837 eyes showed similar anatomic, but worse functional, outcomes when ICG has been used in chromovitrectomy ${ }^{(22)}$. Most of the studies in this meta-analysis used ICG in high concentrations and volumes. The hypotheses of RPE toxicity to retina is based on 2 different mechanisms: 1) The iodine/singlet oxygen released by the ICG molecule especially if irradiated by light and its metabolic derivates damage the RPE ${ }^{(9-11)}$;2) The ICG may affect the cleavage plan from the ILM/neurosensory retina resulting in damage to the retina due to removal of Muller and glia cells during the peeling procedure ${ }^{(23)}$.

ICG has been also used to facilitate ILM peeling in other diseases. Its use in diabetic macular edema (DME) revealed no sign of retinal toxicity, but visual outcome was similar to vitrectomy without $\mathrm{ICG}^{(24)}$. ICG compared to triamcinolone acetonide (TA) in patients with diffuse DME showed no differences ${ }^{(25)}$. Radetzky et al. evaluated ILM peeling with ICG for persistent macular edema due to central retinal vein occlusion, DME, Irvine-Gass syndrome and vitreomacular traction syndrome. Significant improvement in visual acuity was observed only in patients with $\mathrm{DME}^{(26)}$. Large-scale randomized trials should evaluate the benefit and safety of ICG-guided ILM peeling in other diseases ${ }^{(4)}$.

\subsection{Infracyanine green}

Infracyanine green (IfCG) is the modified version of ICG that does not contain 5\% sodium iodide used for the lyophilized form necessary for dye-solubility. It stains ILM homogenously, but not epiretinal membranes, a cellular tissue. Similar to ICG, this iodine-free dye also binds with high affinity to the ILM and 


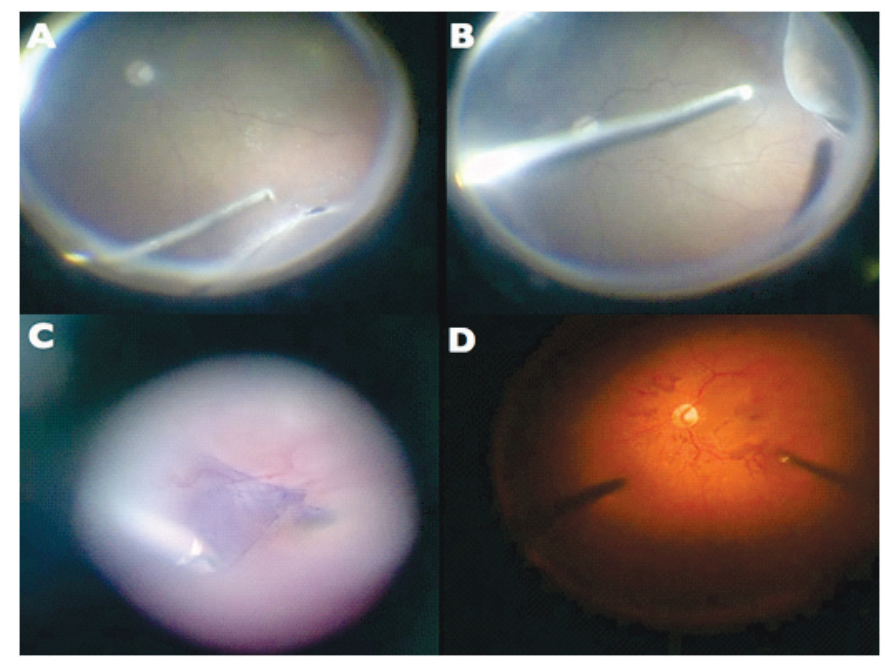

Figure 6: Intraoperative view of macular hole surgery submitted to ILM peeling guided by brilliant blue $0.5 \%$ staining - Ophthblue ${ }^{\mathrm{TM}}$ (Ophthalmos, Brazil) using the different light sources: A - Vitreous base removal after phacoemulsification, IOL implantation and posterior hyaloid detachment. The periphery of the retina is observed by the surgeon's indentation of the sclera using the xenon light source - Photon II (Synergetics, USA) in a $4^{\text {th }}$ sclerotomy; B - A more advanced stage of vitreous base removal. The high definition of the image allows visualization of possible retinal tears; $\mathrm{C}$ - The ILM peeling guided by brilliant blue staining and the use of ambar filter from the Stellaris PC $^{\mathrm{TM}}$ light source (Bausch \& Lomb, USA); note the easy observation of ILM around the macular hole; D - Fluid air exchange using the ambar filter from the Stellaris PC ${ }^{\mathrm{TM}}$ light source (Bausch \& Lomb, USA). No dispersion of light is observed due to the light pipe

facilitates its visualization. The dilution of IfCG in glucose $5 \%$ generates an iso-osmotic solution $(294-314 \mathrm{mmoL} / \mathrm{kg})$, thereby reducing the risks of hypo-osmotic-induced toxicity previously reported with ICG. Indeed, osmolarity changes at the vitreoretinal interface or subretinal space induced by various types of solutions have been shown to be toxic to retinal cells and tissue ${ }^{(4)}$.

Several clinical investigations have shown little or no retinal toxicity with IfCG application. IfCG-assisted ILM peeling demonstrated closure rates over $90 \%$ of $\mathrm{MH}$ and an improvement in visual acuity ${ }^{(27,28)}$. In surgical ILM removal for DME, IfCG appeared to be safe and to promote good clinical results ${ }^{(29)}$. Nevertheless, controlled clinical studies showed that IfCG-guided peeling did not significantly improve the results of MH surgery ${ }^{(8,30)}$.

Immunohistochemical analysis of the ILM peeled with IfCG showed the presence of remnants of footplates from Muller, glial cells and neural or ganglion cells ${ }^{(31)}$. This could explain why in cadaver eyes, IfCG as well as ICG followed by illumination may alterate the cleavage plane at inner retinal layers of the $\operatorname{ILM}^{(32)}$. Therefore, although IfCG and ICG may facilitate ILM removal, they may produce undesired retinal alterations in the neurosensorial retina, RPE and lead to visual field defects ${ }^{(32,33)}$. In summary, a safer IfCG profile may make it a better alternative than ICG for chromovitrectomy in humans, since IfCG in the concentration of $0.5 \mathrm{mg} / \mathrm{ml}$ allows ILM identification with fewer toxic effects.

\subsection{Brilliant blue}

Brilliant Blue G (BBG), also known as Coomassie or Acid

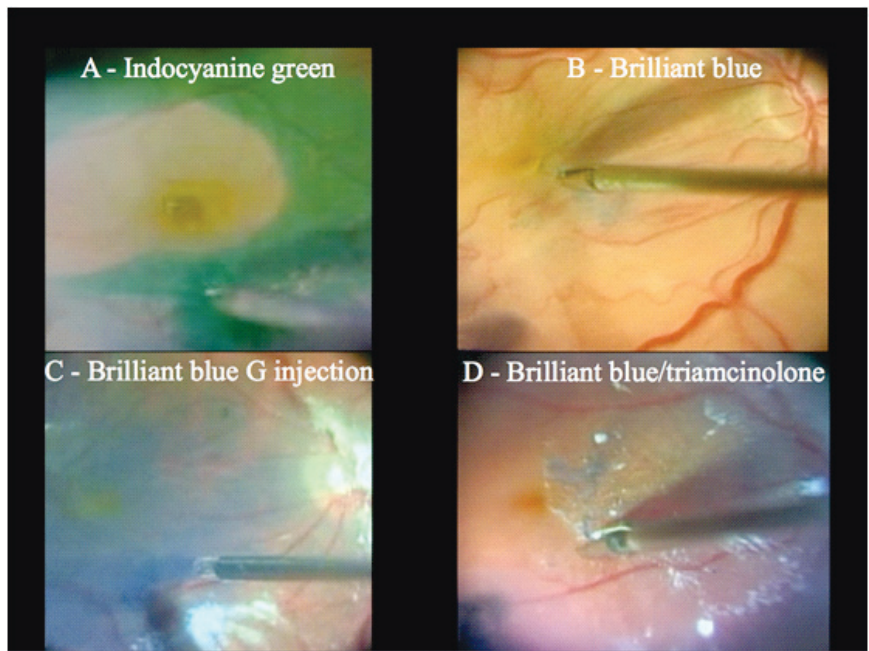

Figure 7: Summary of the ILM peeling techniques during the chromovitrectomy: A - ILM peeling guided by ICG staining $0.5 \mathrm{mg} /$ $\mathrm{mL}$ in macular hole. A fast surgical procedure is advised and the light pipe must be held far from the macula to mimize the possibility of toxic effects; B - ILM peeling guided by brilliant blue $0.5 \mathrm{mg} / \mathrm{mL}$ in macular hole surgery; C - Brilliant blue $0.5 \mathrm{mg} / \mathrm{mL}$ injection using the soft tip during the infusion off. Care to avoid intense flush of the dye is necessary; ILM peeling guided by the double staining technique after ERM removal. Staining was performed by $0.2 \mathrm{~mL}$ of triamcinolone acetonide $40 \mathrm{mg} / \mathrm{mL}$ along with $0.2 \mathrm{~mL}$ of $0.5 \mathrm{mg} / \mathrm{mL}$ of brilliant blue

Blue, is a synthetic dye that has been certified as safe food additive in Europe and may be used as protein gel electrophoresis marker in cardiovascular and neurologic diseases ${ }^{(8)}$. In chromovitrectomy the safety profile of BBG was investigated in pre-clinical experiments with no significant retinal alterations at low dosage of $0,5 \mathrm{mg} / \mathrm{mL}$ at ILM peeling in primates $^{(34)}$.

In humans, BBG produced appropriate ILM staining in an iso-osmolar solution of $0.25 \mathrm{mg} / \mathrm{mL}$ when used for idiopathic ERM and $\mathrm{MH}$ treatment. $85 \%$ of eyes improved at least two Snellen lines, with no signs of toxicity ${ }^{(35)}$.

Similar outcomes were reported even using multifocal electroretinogram to evaluate retinal toxicity ${ }^{(36)}$. Since this dye has good affinity for the ILM, BBG double staining may help simultaneous ERM and ILM peeling with no apparent effect on visual acuity. Moreover this technique appears to reduce subsequent ERM recurrence ${ }^{(37)}$.

$\mathrm{BBG}$ is emerging as a good alternative for ICG and IfCG in chromovitrectomy because of its remarkable affinity for ILM (figures 5 and 7B). The basic studies about the toxicity profile of brilliant blue over the EPR lower than indocyanine green and such technique using this blue dye is the most worldwide performed ${ }^{(36)}$. Additionally, the combination of the new light filters, especially the ambar filter from the Stellaris $\mathrm{PC}^{\mathrm{TM}}$ (Bausch\&Lomb, USA), in combination with brilliant blue results in a high contrast and very good observation of ILM performed by a group of independent vitreoretinal surgeons worldwide with more than 300 surgeries performed, demonstrating that ambar light and brilliant blue facilitates the ILM identification and 
Table 1

Comparison of substances currently used in chromovitrectomy

\begin{tabular}{|c|c|c|c|c|c|}
\hline Substance & $\begin{array}{l}\text { Dilution/ } \\
\text { Osmolarity }\end{array}$ & $\begin{array}{l}\text { Affinity for } \\
\text { intraocular } \\
\text { structures }\end{array}$ & $\begin{array}{l}\text { Avoiding RPE/ } \\
\text { Retina toxicity }\end{array}$ & High cost & $\begin{array}{l}\text { Chemical } \\
\text { properties }\end{array}$ \\
\hline $\begin{array}{l}\text { Patent blue } \\
2.5 \mathrm{mg} / \mathrm{mL} 0.25 \%\end{array}$ & $\begin{array}{l}\text { No dilution or mix } \\
\text { with glucose } \\
2.5 \mathrm{mg} / \mathrm{mL} \\
(0.25 \%) / 290 \mathrm{mOsm}\end{array}$ & ERM & $\begin{array}{l}\text { Use with no dilution } \\
\text { or mix } 0.3 \mathrm{~mL} \text { with } \\
0.1 \mathrm{~mL} \text { glucose } 5 \% \\
\text { for better ERM } \\
\text { identification }\end{array}$ & ++ & $\begin{array}{l}\text { Patent blue is } \\
\text { a triarylmethane dye } \\
(\mathrm{C} 27 \mathrm{H} 31 \mathrm{~N} 2 \mathrm{NaO} 6 \mathrm{~S} 2 ; 582 \text { daltons })\end{array}$ \\
\hline $\begin{array}{l}\text { Brilliant blue } \\
0.25 \mathrm{mg} / \mathrm{ml} 0.025 \%\end{array}$ & No dilution/280 mOsm & ILM & Use with dilution & +++ & $\begin{array}{l}\text { Brilliant blue is a blue } \\
\text { anionicaminotriarylmethane } \\
\text { compound } \\
\text { (C47H48N3S2O7Na; } 854 \text { daltons) }\end{array}$ \\
\hline $\begin{array}{l}\text { Indocyanine green } 5 \mathrm{mg} \text {, } \\
0.5 \% ; 25 \mathrm{mg}, 2.5 \% \text {; } \\
50 \mathrm{mg}, 5.0 \%\end{array}$ & $\begin{array}{l}\text { Less than } 0.5 \mathrm{mg} / \mathrm{mL} \\
(0.05 \%) \text { Dissolve in } \\
\text { small amount of } \\
\text { distilled water. } \\
\text { Dilution:use large } \\
\text { amount of BSS }\end{array}$ & ILM & $\begin{array}{l}\text { Add } 1 \mathrm{ml} \text { distilled } \\
\text { water to } 1 \text { vial } 5 \mathrm{mg} \\
\text { Take } 0.1 \mathrm{~mL} \text { of the } \\
\text { solution and } \\
\text { mixwith } 0.9 \mathrm{ml} \text { BSS }\end{array}$ & ++++ & $\begin{array}{l}\text { Indocyanine green is a } \\
\text { tricarbocyaninedye } \\
\text { (C43H47N2NaO6S2; 775daltons) } \\
\text { and contains } 3 \text { to } 5 \% \text { iodine }\end{array}$ \\
\hline $\begin{array}{l}\text { Infracyanine green } \\
5 \mathrm{mg}, 0.5 \%, 25 \mathrm{mg}, 2.5 \%\end{array}$ & $\begin{array}{l}\text { Less than } 0.5 \mathrm{mg} / \mathrm{mL} \\
(0.05 \%) \text { Dissolve } \\
\text { in glucose } \\
5 \% / 290 \mathrm{mOsm}\end{array}$ & ILM & $\begin{array}{l}\text { Add } 1 \text { or } 2 \mathrm{~mL} \\
\text { glucose } 5 \% \text { to } \\
1 \text { vial of } 5 \mathrm{mg}\end{array}$ & +++++ & $\begin{array}{l}\text { Infracyanine green has the } \\
\text { same chemical formula as ICG } \\
\text { butcontains no sodium iodine }\end{array}$ \\
\hline
\end{tabular}

removal (Chow, D. Vail Vitrectomy Meeting 2013)(figure 6).

Although brilliant blue staining of the ILM has been considered the best alternative for ILM peeling, uneventful subretinal migration of such dye during macular hole surgery may also cause RPE defects a the site of the brilliant blue migration probably related to the effect of singlet oxygen following light exposure; for this reason, the research of additional dyes with antioxidant properties for ILM peeling in macular hole surgery is an interesting field of research. ${ }^{(38)}$

\subsection{Triamcinolone acetonide}

Kimura et al. first used TA for ILM peeling, observing that the white specks and crystals deposit over the ILM, thereby facilitating its identification and removal. They obtained good clinical results and observed no adverse effects after three months. Subsequent pathology disclosed the presence of ILM in specimens after TA-assisted peeling, thereby showing that is possible to remove ILM and not just vitreous. ${ }^{(2,8)}$ Since then other studies have confirmed that TA-assisted ILM removal gives good results (figure 7D) ${ }^{(39-41)}$. Compared to ICG-guided ILM removal, a non- controlled study indicates that TA has the same closure rate with significantly better visual results with no side effects ${ }^{(42)}$.

Crystals of TA have been detected up until forty days post surgery with chromovitrectomy for $\mathrm{MH}$ surgery. Some authors suggest that this persistent TA could slow the healing process necessary for $\mathrm{MH}$ closure ${ }^{(4)}$. A recent study compared ILM peeling with and without the use of TA. During a mean follow-up of 7.3 months, no recurrence of the $\mathrm{MH}$ was observed ${ }^{(40)}$. Despite of this concern, preservative-free TA appears to be a preferred agent in chromovitrectomy ${ }^{(43)}$.

\subsection{Trypan blue}

Soon after its introduction in cataract surgery, TB was proposed as a stain for chromovitrectomy ${ }^{(4)}$. However, TB does not enhance ILM- visualization as well as ICG; additionally, TB is recommended mainly for ERM-staining ${ }^{(8)}$. In addition, ILM visualization with TB is much more difficult than with ICGguided $^{(2,44)}$. If TB is used for ILM staining, the dye should be kept in contact with the ILM for a longer period of time than ICG. 
Two comparative studies showed same rate of closure stage II to IV idiopathic MH using ICG or TB. However, vision was significantly better only in the TB-group ${ }^{(44,45)}$.

Although many clinical studies reveal that TB exerted little or no toxic effect to the retina, TB-staining may produce retinal damage, especially at higher concentrations ${ }^{(4,46,47)}$. In the future, clinical investigations should clarify the role of TB in combination with other vital dyes in chromovitrectomy, the so-called double staining, and elucidate the safe dose of intravitreal TB for chromovitrectomy ${ }^{(48)}$.

\section{Summary of ILM peeling techniques}

The ILM technique is a difficult surgical maneuver and very useful for the management o many diseases during vitreoretinal diseases. The surgical techniques that facilitate this procedure are very useful for vitreoretinal surgery. Nowadays the ILM peeling must be performed using the following techniques (figure 7 and table 1): A-Indocyanine green or infracyanine green (this has a lower toxicity profile due to the lack of iodine at the molecular composition); B-Brilliant blue - current used and the "gold standard" dye for this purpose; $\mathrm{C}$-Brilliant blue $\mathrm{G}$ (that requires no flush during injection due to high density) and D-The double staining technique (which involves the use of triamcinolone crystals and brilliant blue).

\section{Vital dyes for epiretinal membranes \\ 2.1. Trypan blue}

Epiretinal membrane is related to glial proliferation over the microtears at the internal limiting membrane resulting in collagen, astrocytes and glial cells proliferation and decrease in visual acuity

Trypan blue is commonly used in microscopy for cellular counting for staining of the reticuloendothelial system and the

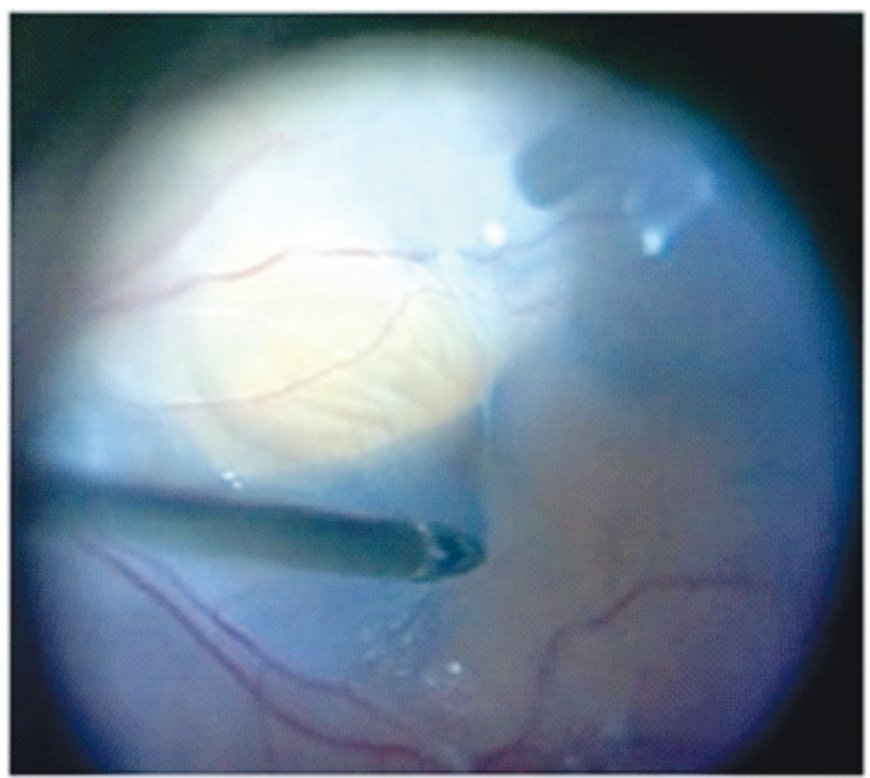

Figure 8: A combination of $0.3 \mathrm{~mL}$ of $\mathrm{TB} 1.5 \mathrm{~mL} / \mathrm{mL}$ and $0.1 \mathrm{~mL} \mathrm{f}$ glucose $5 \%$ solution injected in a fluid-filled technique; this dye solution is denser than water that might avoid contact at the posterior capsule of the lens and is helpful to maintain selective staining of posterior pole kidney tubules. In the late 1990s, TB was shown to have a great affinity to the anterior capsule of the lens, which facilitated capsulorrhexis in cataract surgery. Soon thereafter, TB was tried as a stain for pre-retinal tissues such as the ILM and ERM in chromovitrectomy. The vital stain may traverse cell membranes only in dead cells thereby coloring dead tissues/cells blue; live cells/tissues with intact cell membranes are not stained since their selective control of cellular membrane transport does not allow TB-binding. Thereby, TB exhibits a strong affinity for ERM because of the many dead glial cells within those membranes (figure 8$)^{(8)}$. Various investigators, including our group, agree that $\mathrm{TB}$ is indicated for recognition of ERMs in vitrectomy, as the blue dye enables complete identification of the entire ERM surface ${ }^{(8)}$. TB staining of the ERM may minimize mechanical trauma to the retina during ERM-removal and allows recognition of the extent of the ERM (figure 9C).

Postoperatively median visual acuity difference after macular pucker surgery with and without the use of $0.15 \%$ TB was not statistically significant for a follow-up of four to six months in twenty patients. However, four of 10 patients without and seven of 10 patients with TB-staining experienced an improvement of visual acuity of 2 lines or more ${ }^{(46)}$. One comparative study with TB and ICG for ERM removal also gave results favoring the application of $\mathrm{TB}^{(49)}$.

No RPE defects or signs of retinal toxicity have been reported in most studies. However, in one case report of inadvertent subretinal migration of TB away from the fovea, RPE changes were noted at the migration site, but did not compromised visual acuity ${ }^{(50)}$. Histopathological analysis of excised ERM showed no retinal cells on the retinal side of the ERM and no signs of apoptosis ${ }^{(51)}$. Multifocal ERG found no retinal toxicity ${ }^{(52)}$. Finally, electron microscopy of the TB-stained ERM showed fragments of ILM in all specimens ${ }^{(49)}$. Interestingly, Smiddy and coworkers showed that without the use of any dye, epiretinal membrane fragments contain ILM fragments in $76 \%$ of cases ${ }^{(4)}$. The clinical relevance of those ultra structural findings remains to be determined; however, future controlled studies should clarify if TB has any toxicity.

To enhance dye penetration onto retinal surface in an airfluid-exchange, TB may be mixed with glucose, thereby creating a dye solution denser than water (figure 8, table 1). Lesnik Oberstein et al. used TB and 10\% glucose isovolumetrically in osmolarity of $320 \mathrm{mOsm} / \mathrm{L}$ to evaluate ERM staining without fluidair exchange ${ }^{(53)}$. Just $25 \%$ of eyes needed a reapplication of the solution to achieve ERM staining. In addition all patients exhibited improved visual acuity with no signs of retinal toxicity. However, higher glucose concentrations should be avoided. Injection of $0.05 \mathrm{~mL}$ of a $1000 \mathrm{mOsm}$ solution in animals caused rapid whitening of the posterior retina, followed by the development of a large detachment and permanent retinal degeneration. An ERG showed immediate loss of the c-wave and a slower decline of the a- and b-waves ${ }^{(54,55)}$. Osmolarity should be considered in planning any vitreous injection of dyes and drugs. In summary the trypan blue may be mixed to glucose in order to have a denser solution that goes directly to the posterior pole; however it may be mixed with glucose $5-10 \%$ only ( $25 \%$ of the dye and $75 \%$ of the glucose) in order to avoid and hyperosmotic solution that may damage the retina (Table 1$)^{(19)}$. 


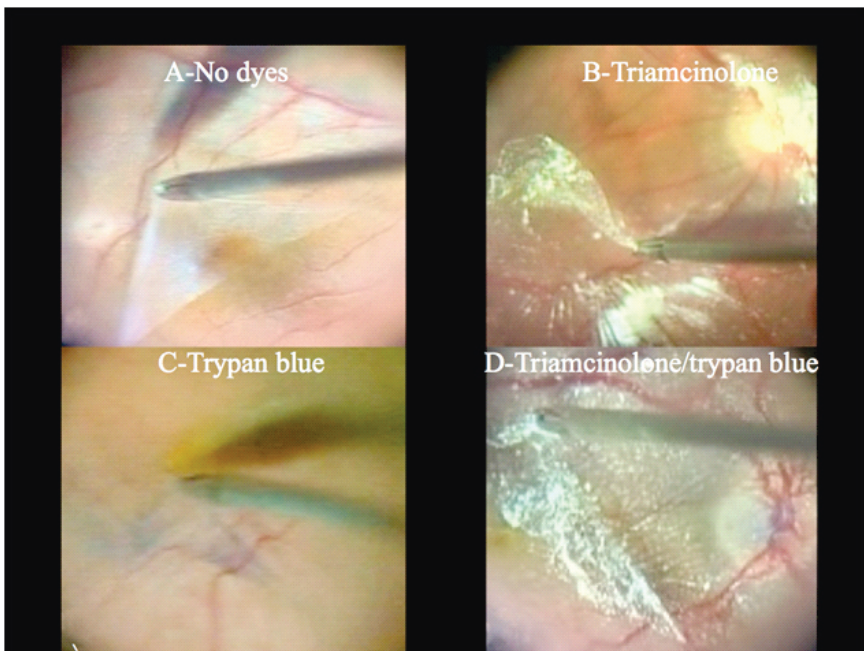

Figure 9: Summary of the ERM peeling techniques during the chromovitrectomy: A - ERM peeling using no dyes; B - ERM peeling using $0.2 \mathrm{~mL}$ of triancinolone ecetonide (TA) $40 \mathrm{mg} / \mathrm{mL}$; C - ERM peeling using trypan blue (TB) $1.5 \mathrm{mg} / \mathrm{mL}$; D - ERM peeling using TA and TB, by the double-staining technique. Staining was performed with $0.2 \mathrm{~mL}$ of TA $40 \mathrm{mg} / \mathrm{ml}$ and $0.2 \mathrm{~mL}$ of TB $1.5 \mathrm{mg} / \mathrm{m}$

\subsection{Patent blue, bromophenol blue and indocyanine green}

These dyes are not current used during chromovitrectomy for ERM identification. However, they are reported in the literature as possible alternatives for this surgical technique.

\subsubsection{Patent blue}

$\mathrm{PB}$ is a fluorescent marker that enables lymph nodes removal and in-vitro fungi specimens identification. The dye has been has been certified for capsule staining during cataract surgery at concentration of $0.24 \%{ }^{(4)}$.

Animal studies and preliminary clinical data demonstrate moderated affinity of patent blue (PB) to ERM and vitreous, but poor affinity to the $\operatorname{ILM}^{(2,8)}$. Nevertheless, our recent clinical data revealed that $\mathrm{PB}$ is as appropriate a vital dye for coloring ERM as $\mathrm{TB}^{(56)}$.

There is conflicting data regarding the retinal toxicity of PB. In one study PB induced only mild and reversible retinal toxicity ${ }^{(57)}$, whereas RPE-cells exposed in vitro to PB showed no toxicity $^{(56)}$. Our rabbit subretinal toxicity model demonstrated that subretinal injection of $\mathrm{PB}$ resulted only in mild ultrastructural retinal damage during follow-up; the histological damage induced by TB was more severe than by $\mathrm{PB}$. Most studies to date indicate a safer profile for $\mathrm{PB}$ compared to $\mathrm{TB}$, particularly in neuroretinal cells. However, the safe dosage range for intravitreal PB injection remains unclear yet.

\subsubsection{Bromophenol blue}

BroB has been used as acid-base indicator and as marker of gel electrophoresis procedures. In comparison to six biological stains (light green yellowish, E68, Chicago blue, rhodamine, rhodulinblau-basic) BroB has stained the ERM and ILM better with no RPE-cell in vitro toxicity or primary proliferation at concentrations of 0.2 and $0.02 \%{ }^{(58)}$. In vivo studies in rodent and porcine eyes demonstrated that $\mathrm{BroB}$ at concentrations of 0.5 and $0.02 \%$ promoted less retinal toxicity as assessed by histology and ganglion cell counts in comparison to three other vital dyes (light-green, Chicago blue, and E68). Moreover BroB at concentrations of 1 and $2 \%$ promoted enhanced ILM coloring and identification ${ }^{(4)}$.

Its first use in humans using $0.2 \%$ concentration showed good staining properties in ERM and vitreous remnants with a good safety profile in a short follow up ${ }^{(59)}$. BroB also helped to visualize posterior hyaloid membrane in $\mathrm{MH}$ surgery and to remove vitreous base during retinal detachment surgery ${ }^{(60)}$.

\subsubsection{Indocyanine green}

ICG has been proposed to allow better visualization of ERMs in vitrectomy for proliferative diabetic vitreoretinopathy (PDVR), idiopathic ERMs, and proliferative vitreoretinopathy $(\mathrm{PVR})^{(2,61)}$. However, the green dye may stain the acellular ILM best, and ERM-staining by other vital stains may be better ${ }^{(8)}$. Foster et al. described a case of recurrent macular hole surgery where ICG stained ILM except in an inferior area with an $\mathrm{ERM}^{(62)}$. The same phenomena were observed in ERM surgery for PVR, where ICG stains ILM but not the ERM facilitating the identification and removal by negative staining ${ }^{(63)}$.

ERM peeling with and without ICG showed no difference in visual acuity or retinal toxicity. More recently, the effect of ILM peeling with and without ICG staining for idiopathic ERM removal demonstrated no difference in preoperative or postoperative visual acuity, reduction of macular edema, or incidence of recurrent $\mathrm{ERM}^{(4)}$.

\section{Summary of ERM peeling techniques}

The ERM peeling technique is not so difficult surgical maneuver such as the ILM peeling and sometimes the surgical procedure maybe performed with no dyes (figure 9A). However, the correct size of ERM is better evaluated after the staining procedures either by deposition of the triamcinolone crystals (figure 9B) or by trypan blue staining - considered the gold standard dye for this purpose (figure 9C). Additionally, the double staining technique with trypan blue and triamcinolone is also very useful for ERM peeling (figure 9D). The surgical techniques that facilitate these procedures are very useful for vitreoretinal surgery.

Nowadays, there is a trend to peel the ERM following by ILM staining with brilliant blue in order to avoid recurrence of epiretinal tissue in either the macular holes or ERMs (Figure $10)^{(64)}$

The ERM peeling must be performed using the following techniques (figure 9): A-No dyes; B-Triamcinolone acetonide deposition; C-Trypan blue staining and D-The double staining technique (which involves the use of triamcinolone crystals deposition and also trypan blue staining) ${ }^{(19)}$.

\section{Subretinal vital dye for facilitation of retinal breaks visualization}

Exact localization of retinal breaks is a critical step in the surgical treatment of rhegmatogenous retinal detachment (RD) ${ }^{(65)}$. Despite clear visualization of the fundus, in 2.2 to $4 \%$ of phakic RDs, the retinal breaks may not be found. In aphakic and pseudophakic RDs, the incidence of nonvisualized breaks may be even higher ranging from 7 to $16 \%$ and 5 to $22.5 \%$, respectively ${ }^{(66)}$. 


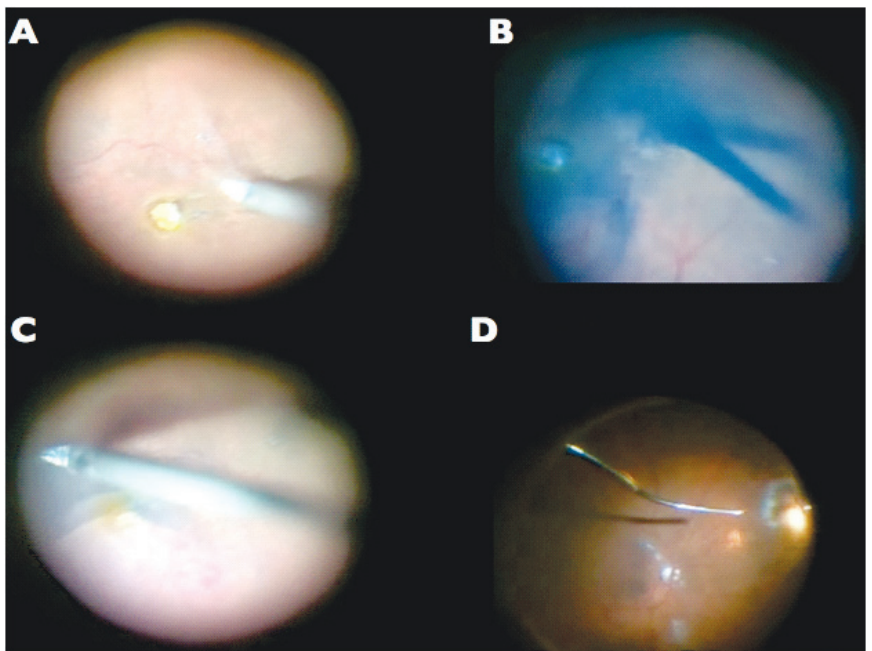

Figure 10: Intraoperative view of chronic macular hole and ERM. After ERM peeling, the ILM is stained for facilitate the peeling procedure: A - Epiretinal peeling using intraocular forceps. Note that triamcinolone previously used for posterior hyaloid detachment is observed into the macular hole; B - Intravitreal injection of brilliant blue (BB) $0.5 \mathrm{mg} / \mathrm{mL}$; C- ILM - peeling guided by BB staining; DFluid air exchange following by laser at the iatrogenic tear

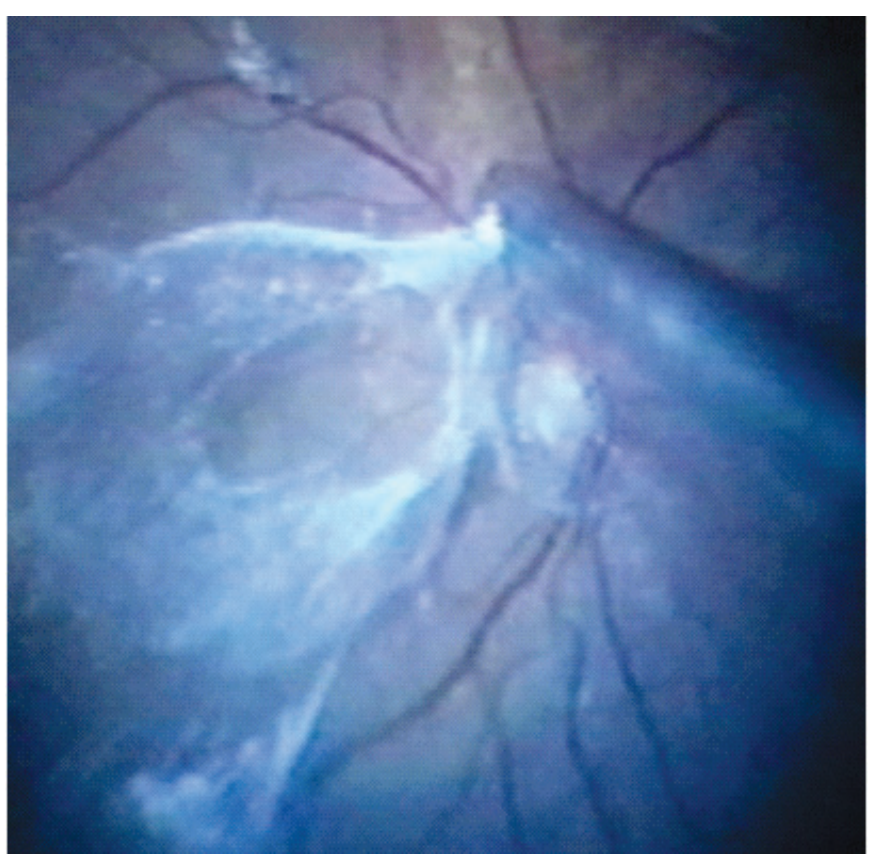

Figure 11: Triancinolone acetonide - guided posterior hyaloid dissection; note that TA crystals deposits to the acellular vitreous gel, providing a clear visualization of the posterior vitreous cortex

\subsection{Clinical application of vital dyes for subretinal breaks identification}

The first use of subretinal application of dyes to stain retinal breaks was made in 1947 by Black. He used methylene blue through a transcleral needle. This vital dye application was considered unsuccessful by Hruby and Gass because of its absorption in the retinal pigment epithelium. Later, Kutschera showed that systemic infusion of PB enabled both understanding of retinal metabolism and absorption in animals, which provided further evidence for the role of staining agents in the recognition of retinal breaks. Recently, Jackson et al. applied subretinal $0.15 \%$ TB with a 41-gauge cannula to identify retinal breaks in patients with RD and no identifiable tears during surgery. Retinal breaks were identified in 4 of the 5 patients, and no retinal toxicity was seen in this study. However, the small number of patients does not allow assessment of the risks and potential toxicity ${ }^{(4,65)}$. Despites this is an elegant surgical technique, this is not currently used in chromovitrectomy due to the risks of RPE damage as well as the high quality of the intraoperative vision minimizing the necessity of this surgical technique.

\section{Vital dyes for vitreous}

The vitreous plays a very active and important role in several vitreoretinal diseases, including macular holes, macular edema, diabetic retinopathy and retinal detachment. In vitreoretinal surgery for therapy of those diseases, complete removal of the vitreous gel may enhance surgical outcomes ${ }^{(67)}$.

\subsection{Triancinolone acetonide}

TA deposition onto the vitreous surface was initially reported by Peyman et al in 2000 . The crystals of the crystalline steroid adhere to the acellular tissue, thereby enabling a clear contrast between the empty vitreous cavity and the areas where the vitreous fibers are still present. Nowadays, TA is the most used substance for vitreous identification and the currently technique application consists of a simple injection of the agent into the vitreous cavity (figure 11).

Following the initial report, a number of studies confirmed the efficacy of TA for staining the transparent vitreous, whereas anatomic or functional signs of complications have rarely been observed $^{(4,8,68)}$. In addition to its effect on the vitreous visualization, a TA injection during vitrectomy may prevent fibrin reaction and post-operative PVR; however, there is no conclusive data about this possible effect. The use of intraoperative TA during vitreoretinal surgery showed decreased risk of post-operative RD, but increased need for postoperative hypotensive eyedrops ${ }^{(4,8)}$.

The safety of TA to the retina has been demonstrated by several in-vitro and in-vivo studies ${ }^{(8)}$; intravitreal injection of TA in high concentration (up to $30 \mathrm{mg}$ ) yielded no relevant retina toxicity, while our investigation disclosed no damage to the retinal tissue after subretinal preservative-free TA-injection in rabbits $^{(69)}$. It has been recently proposed that the preservative benzyl alcohol present in TA-vehicle induce most retinal damage and nowadays the crystals deposition of TA is considered the gold standard substance for posterior hyaloid and vitreous base identification (figure 10 and table 1$)^{(19,70)}$.

\section{Sodium fluorescein, Fluorometholone acetate and Trypan blue}

These dyes are not current used during chromovitrectomy for vitreous identification; however, they are reported in the literature as possible alternatives for this surgical technique.

\subsection{Sodium fluorescein}

Hydrophilic sodium fluorescein (SF) is exceedingly well absorbed by the vitreous. Improved visualization of clear vitreous fibers by intravitreal SF $0.6 \%$ showed no complications ${ }^{(71)}$. 

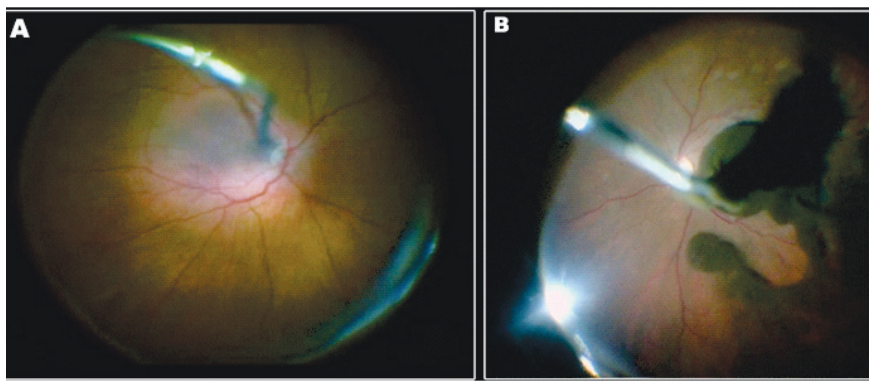

Figure 12: Lutein $0.3 \%$ and BB $0.025 \%$ deposit onto the posterior pole during vitrectomy for ERM: A - Intraoperative view of the injection. The higher density of the dye allows gentle deposition onto the posterior pole without the need for pressurized injection; B Widespread staining of the posterior pole obtained by deposition of the solution

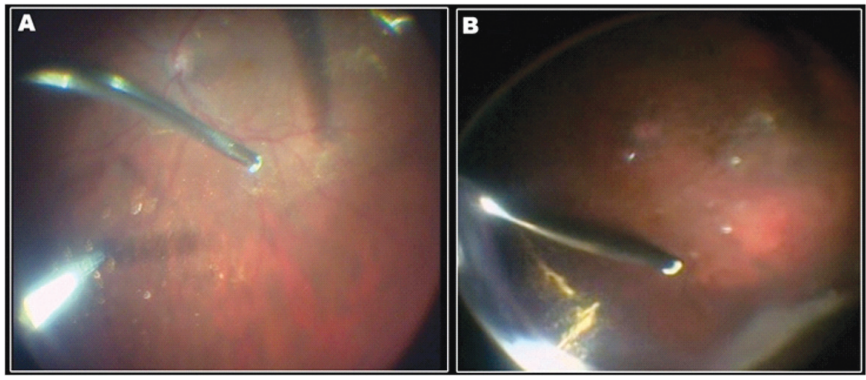

Figure 13: Dye deposition at the posterior hyaloid and vitreous base in an eye with a macular hole: A - The posterior hyaloid is detached and identified by deposition of the lutein crystals; B -The late stage of removal of the vitreous base aided by the golden crystals

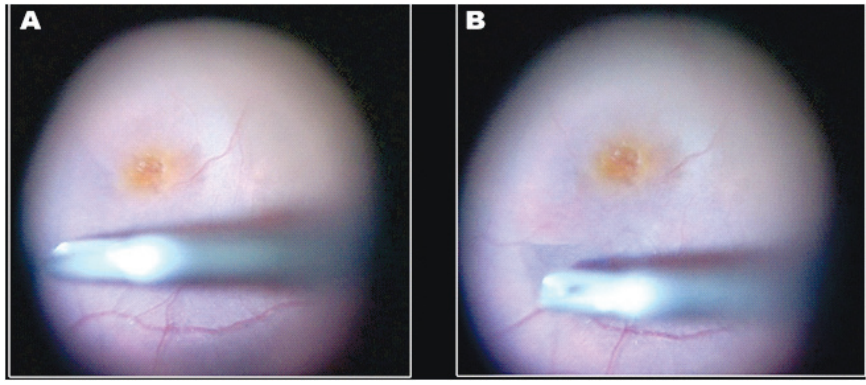

Figure 14: Dye deposition at the ILM in an eye with a macular hole; A - An intraoperative image shows the initial removal of the ILM stained blue by BB; B - The intermediate phase of ILM peeling shows the tip of the forceps grasping the blue-stained ILM

Comparison of four different vital vitreous stains found that fluorescein was inferior to the $\mathrm{TA}^{(72)}$. Currently, the main use of $\mathrm{SF}$ in chromovitrectomy is vitreous staining and future clinical investigations should determine its role to improve visualization of membranes during vitreoretinal surgery.

\subsection{Fluorometholone acetate}

The fluoremetholone acetate (FMA) white to creamy powder may be prepared for ophthalmic suspension. The white steroid may be indicated for use in the treatment of steroidresponsive inflammatory conditions of the conjunctiva, cornea, and anterior segment of the eye. The safety of intravitreal or subretinal FMA to retina has been recently examined in rat and primate eyes. The researchers found neither remarkable reduction in any ERG waves, or histological changes, and concluded the steroid FMA was a useful alternative to TA during chromovitrectomy ${ }^{(73)}$. Further clinical experience should elucidate the advantages and disadvantages of FMA in comparison to TA and other newer vital dyes.

\subsection{Trypan blue}

Intracameral or intravitreal injection of TB has been used to highlight vitreous. The blue dye in various doses may improve detection of both prolapsed vitreous in the anterior chamber and that remaining in the vitreous cavity. $0.15 \% \mathrm{~TB}$ used for staining the vitreous produced no toxicity ${ }^{(8)}$. TB may allow visualization of the margins of the vitreous strands during vitreoretinal surgery ${ }^{(74)}$. However, in one comparative analysis TB stained the vitreous less well than TA and $\mathrm{FS}^{(72)}$. For this reason TB application for vitreous visualization has not gained much popularity.

\section{Summary of posterior hyaloid identification technique}

The posterior hyaloid and vitreous base identification in nowadays performed by micronized triamcinolone acetonide crystals deposition and this surgical technique is current used for our research team in all vitreoretinal procedures, which is especially useful for diabetic retinopathy in young patients, macular holes, vitreomacular traction syndrome, ocular trauma and primary vitrectomy for retinal detachment repair (figure 11 and table 1$)^{(19)}$.

\section{Surgical Techniques for dye application during vitreoretinal surgery}

\subsection{Double staining technique}

The double-staining technique is an elegant procedure that may facilitate the identification of the posterior hyaloid and ILM (figures 7D and 11) as well as the posterior hyaloid and ERM (figure 9D and 11). In this technique, the initial step consists in the injection of a dye with high affinity to the vitreous to enable vitreous removal (triamcinolone acetonide - table 1), followed by a second injection of a dye such as infracyanine green, ICG, $\mathrm{TB}$ or BBG to stain and peel pre-retinal membranes (Figures $7 \mathrm{D}$ and $9 \mathrm{D})^{(8,19)}$. As an alternative technique, two dyes may be injected initially before both peeling procedures. Some authors do prefer to name double staining as injection of a dye to peel ERM followed by an additional injection of another dye for ILM peeling ${ }^{(48)}$. Double staining can be performed with either different dyes or in some instances the same coloring agent can be used to stain two intraocular tissues ${ }^{(37)}$.

\subsection{Reconstitution, Dilution and Concentration}

Careful selection of the best solvents for vital dyes for chromovitrectomy should be performed, especially regarding those agents provided as a powder for reconstitution by the surgeon in the operating room, such as ICG.

ICG contains iodine to enhance its solubility, and must be dissolved in pure water to avoid precipitation and diluted again with BSS to avoid a hypo-osmolar solution. IfCG green does not contain iodine, precipitates in water, and glucose $5 \%$ is rather used as solvent. Thereby, IfCG is an alternative to avoid hypoosmolar effect on the retina ${ }^{(19)}$. 

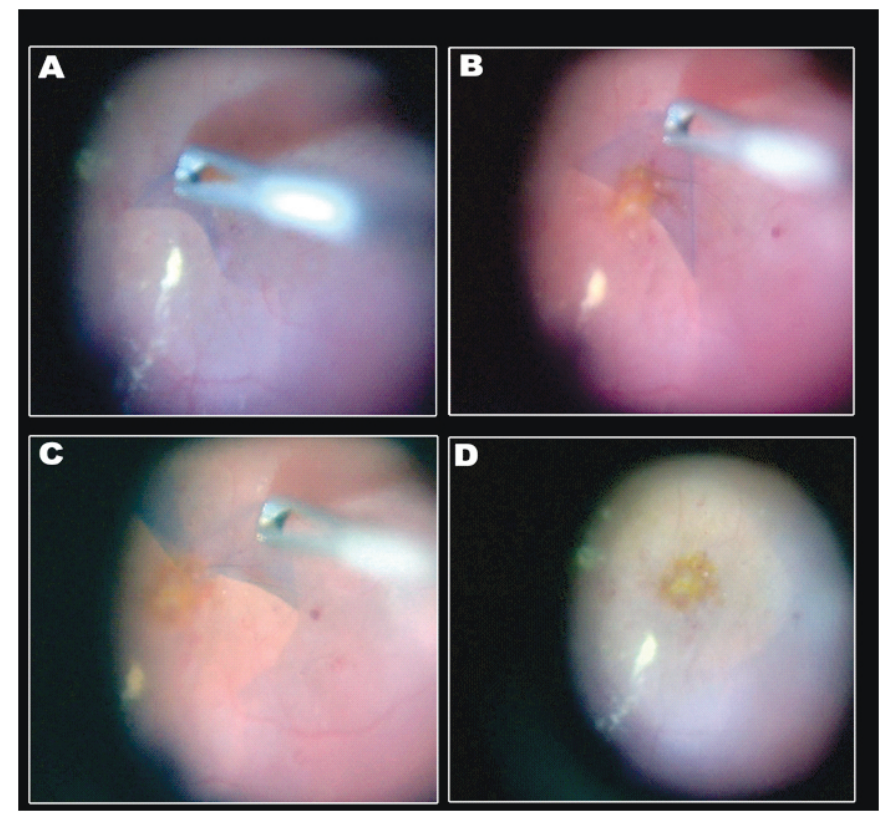

Figure 15: ILM peeling guided by the combination dye in an eye with PDR and macular edema; A - An intraoperative image shows the initial ILM peeling in a patient with PDR and DME; the initial traction can be seen at the ILM, which is stained blue; the underlying retina is not stained blue. The hard exudates under the macular edema have a yellowish appearance; B - The intermediate stage of en bloc ILM removal; the yellowish-orange region in the foveal region characterizes the retinal edema and adjacent macular cysts; $\mathrm{C}-$ The late stage of ILM removal; the fovea is swollen; D - The final stage of ILM peeling

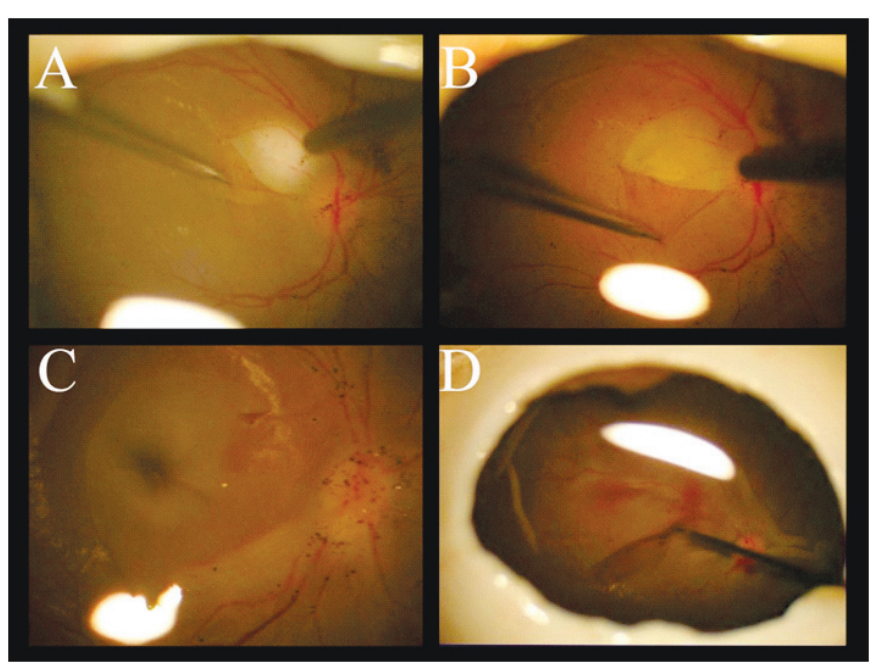

Figure 16: Intraoperative findings during ILM peeling in cadaveric eyes guided by staining with anthocianins from açai fruit (Euterpe Oleracea): A - Initial surgical procedure; B - Progression of ILM peeling procedure; $\mathrm{C}$ - ILM peeling is completed for 360 degrees; D ILM removed completely from cadaveric eye

Staining with minimum concentrations should be enough to distinguish transparent tissues for removal with the underlying semitransparent retina over an orange-reddish background. A low concentration has also the rationale to cause minimal or no toxic effects to retina, RPE or loss of vision (table 1).

\subsection{Dye Injection}

Several different techniques have been used to inject vital dyes in the vitreous cavity. One has been named the "dry method" or "air-filled technique". Whatever, this consists of removing the fluid in the vitreous cavity by a fluid-gas exchange before dye injection. While this has the advantage of concentrating the dye in the posterior pole and avoiding contact at the posterior capsule of the lens, it may expose the retinal surface to a higher concentration of dye ${ }^{(2)}$. When the eye is air filled, the full concentration of dye injected into the vitreous cavity reaches the retinal surface.

The second technique is called the "wet method" or "fluidfilled technique". In this approach, the intravitreal fluid (usually balanced salt solution) is left inside the vitreous cavity while the surgeon injects the dye. The concentration of the dye in contact with the retinal surface is lower because it is diluted by the fluid at the vitreous cavity. The disadvantage to this technique is the possible dispersion of the dye leading to unwanted staining of the retina elsewhere. Comparison of the two methods in a porcine model concluded that the air-filled technique induced a higher incidence of RPE atrophy and outer retinal degeneration ${ }^{(75)}$. A further concern is incubation time of the dye on the retinal surface. Since early dye washout minimizes exposure on retinal tissue, there is a trend to wash out the dye a few seconds after its injection ${ }^{(76,77)}$.

\subsection{Macular hole protection}

There are some ways to avoid dye injection directly through the MH: slow injection of the dye, selective painting instrument (Vince), or placing substances over the MH such as perfluorocarbons liquids (PFCL), autologous whole blood, or sodium hyaluronate. Although interesting surgical techniques, they are not current used for the majority of vitreoretinal surgeons worldwide ${ }^{(4,19,77-79)}$.

\subsection{Illumination}

Vital dyes are small chemical substances that pass freely through retinal tissue and may play a role in or exacerbate retinal phototoxicity from intraoperative light exposure. Photosensitizing dyes could enhance phototoxicity by increasing levels of free radicals, creating a photoproduct that could be harmful to retinal cells and shifting light absorbance from one site of the retina to another. Clinically, consecutive experiments have shown histologic and functional damage to the retina after light plus ICG exposure in comparison to light without dye application ${ }^{(80-82)}$.

To analyze the risk for dye-induced light damage, the spectral overlap between light source emission and vital dye absorbance should be known ${ }^{(80)}$. Haritoglou et al. ${ }^{(80)}$ proposed that a shift in the absorbance band of ICG during vitreoretinal surgery induces photosensitizing effects on the retinal surface. They demonstrated that the absorbance spectrum of ICG overlaps partially with the emission spectrum of one type of halogen light source and that ICG absorbance varies, depending on solvent and osmolarity. Notably, ICG in glucose 5\% shifts the absorbance bands to higher wavelengths compared with ICG prepared in PSS, thereby decreasing the risk for spectral overlap with the light emission source ${ }^{(80)}$.

The light pipe should be kept far from the retina and turned 
off when possible to minimize ICG-related decomposition and thermal damage ${ }^{(19)}$. Additionally, safer profiles of light sources may be used by the surgeon ${ }^{(80)}$.

\section{Future perspectives}

A previous study reported that a solution containing lutein/ zeaxanthin $0.3 \%$ crystals and BB $0.025 \%$ efficiently stained the vitreous, ILM, and posterior hyaloid in cadaveric eyes ${ }^{(81)}$. Clinical, histologic, and electroretinographic evaluations after intravitreal injections of these concentrations of the dyes in rabbit eyes showed no signs of toxicity (Barroso et al. Graefes Arch of Clin and Exp Ophthalmol. Under review). Both studies supported the decision to test the use of lutein/zeaxanthin $0.3 \%$ and BB $0.025 \%$ during chromovitrectomy in human eyes.

A prospective study was performed in 12 eyes followed by 6 months and demonstrated the combination of lutein/ zeaxanthin $0.3 \%$ and $\mathrm{BB} 0.025 \%$ resulted in a green dye (figure 12). The mean initial BCVA improved in all eyes with no signs of by clinical, OCT, fluorescein angiography and visual fields evaluations (Maia et al., Retina. Under review). The final green solution was denser than BSS and was not necessary to flush it into the posterior pole resulting in a fast deposit onto the posterior pole (figure 13). The deposition of the micronized crystals of lutein/zeaxanthin over the posterior hyaloid and within the peripheral vitreous fibers, resulted in a golden appearance of these structures (figure 13); the ability of the BB to stain the ILM resulted in easier ILM peeling in eyes with macular holes, PDR, and DME (figure 14 and 15), (Maia et al., Retina. Under review). Although a high potential to use in human eyes, an additional clinical trial performed by high number of surgeons is ongoing in order to allow the clinical use of such dye - source: www.clinicaltrials.gov (NCT01627977).

Blue light is a major generator of hydroxyl radical, a reactive oxygen species (ROS) that damages biologic structures such as the photoreceptors and RPE. ROS are generated continuously in the retina ${ }^{(83)}$; due to a polyenic chain, lutein and zeaxanthin from the macula donates an electron to the ROS and quenches the triplet stage of singlet oxygen, which inhibits further formation of ROS and prevents lipo-peroxidation ${ }^{(83-86)}$. Based on these findings, we hypothesized that this dye may be safe; however, additional experimental and clinical studies are necessary to confirm this hypotheses.

New natural dyes are under evaluation by studies in cadaveric eyes and the anthocyanins from açaí dye (Euterpe oleracea) demonstrated a high affinity for the ILM in cadaveric eyes (figure 16). Additional basic and clinical studies are necessary to develop the final product useful for chromovitrectomy in human eyes ${ }^{(87)}$.

\section{Conclusions and recommendations}

Vital dyes for chromovitrectomy are emerging tools that may enable better visualization of transparent and fine intraocular tissues. The intraoperative staining facilitates surgical removal and thereby better surgical success. A gentle maneuver to deliver the dye over the target tissue, avoiding the agressive flush injection, while the BSS infusion is turned off, is advised and all the substances used inside the vitreous cavity should have osmolarity around 280-300mOsm and $\mathrm{Ph}$ around 7.00 .

Regarding the specific substances to be used at the different surgical maneuvers, it is recommended:

A) The triamcinolone acetonide is the "gold standard" substance for vitreous base as well as posterior hyaloid identification; around $0.3 \mathrm{~mL}$ should be used in a $40 \mathrm{mg} / \mathrm{mL}$ concentration and no benzyl alcohol on its composition;

B) The trypan blue is the ideal dye for ERM identification; $0.2-0 / 3 \mathrm{~mL}$ of the dye in a $1.2-1.5 \mathrm{mg} / \mathrm{mL}$ concentration should be used. The mixture with glucose $5-10 \%$ may be used $(25 \%$ of glucose and $75 \%$ of the dye), but is not necessary in order to increase the density of the dye to deposit into the posterior pole. The surgeon must wait 5-10 seconds after the injection to turn on the infusion and continue the surgical procedure;

C) The brilliant blue is the ideal dye for ILM identification; $0.2-0 / 3 \mathrm{~mL}$ of the dye in a $0.25 \mathrm{mg} / \mathrm{mL}$ concentration should be used. The mixture with glucose $5-10 \%$ may also be helpful $(25 \%$ of glucose and $75 \%$ of the dye), but is not necessary in order to increase the density of the dye to deposit into the posterior pole. The surgeon must wait 5-10 seconds after the injection to turn on the infusion and continue the surgical procedure;

D) The combination of brilliant blue $0.25 \mathrm{mg} / \mathrm{mL}$ and lutein $3 \mathrm{mg} / \mathrm{mL}$ may be an alternative in order to perform different surgical steps using only one dye with the advantages to avoid the flush of the dye into the vitreous cavity/posterior pole and a possible safety profile due to a "quencher" effect of the lutein molecule over the singlet oxygen molecules generated by the brilliant blue exposed to light during the surgical procedures; these hypotheses may be confirmed by future studies;

E) Additional natural dyes for chromovitrectomy has been evaluated.

\section{ReferenCeS}

1. Burk SE,Da Mata AP,Snyder ME, Rosa RH Jr,Foster RE. Indocyanine green-assisted peeling of the retinal internal limiting membrane. Ophthalmology. 2000;107(11):2010-4.

2. Rodrigues EB, Meyer CH, Kroll P. Chromovitrectomy: a new field in vitreoretinal surgery. Graefes Arch Clin Exp Ophthalmol. 2005;243(4):291-3.

3. Mello Filho PA, Maia M, Rodrigues EB, Farah ME. [Ocular pharmacology in the treatment of vitreous, retina and choroid diseases]. Arq Bras Oftalmol. 2010;73(3):294-9.

4. Rodrigues EB, Costa EF, Penha FM, Melo GB, Bottós J, Dib E, et al. The use of vital dyes in ocular surgery. Surv Ophthalmol. 2009;54(5):576-617. Review.

5. Mester V, Kuhn F. Internal limiting membrane removal in the management of full-thickness macular holes. Am J Ophthalmol. 2000;129(6):769-77. Review.

6. Gandorfer A, Haritoglou C, Kampik A, Charteris D. Ultrastructure of the vitreoretinal interface following removal of the internal limiting membrane using indocyanine green. Curr Eye Res. 2004;29(45):319-20.

7. Wollensak G, Spoerl E, Wirbelauer C, Pham DT. Influence of indocyanine green staining on the biomechanical strength of porcine internal limiting membrane. Ophthalmologica. 2004;218(4):278-82.

8. Rodrigues EB, Maia M, Meyer CH, Penha FM, Dib E, Farah ME. Vital dyes for chromovitrectomy. Curr Opin Ophthalmol. 2007;18(3):17987. Review. 
9. Maia M, Haller JA, Pieramici DJ, Margalit E, de Juan E Jr, Farah ME, et al. Retinal pigment epithelial abnormalities after internal limiting membrane peeling guided by indocyanine green staining. Retina. 2004;24(1):157-60.

10. Maia M, Kellner L, de Juan E Jr, Smith R, Farah ME, Margalit E, et al. Effects of indocyanine green injection on the retinal surface and into the subretinal space in rabbits. Retina. 2004;24(1):80-91.

11. Maia M, Margalit E, Lakhanpal R, Tso MO, Grebe R, Torres G, et al. Effects of intravitreal indocyanine green injection in rabbits. Retina. 2004;24(1):69-79.

12. Arevalo JF, Garcia RA. Macular hole surgery complicated by accidental massive subretinal indocyanine green, and retinal tear. Graefes Arch Clin Exp Ophthalmol. 2007;245(5):751-3.

13. Brazitikos PD, Androudi S, Tsinopoulos I, Papadopoulos NT, Balidis M, Georgiadis N. Functional and anatomic results of macular hole surgery complicated by massive indocyanine green subretinal migration. Acta Ophthalmol Scand. 2004;82(5):613-5.

14. Hirata A, Inomata Y, Kawaji T, Tanihara H. Persistent subretinal indocyanine green induces retinal pigment epithelium atrophy. Am J Ophthalmol. 2003;136(2):353-5.

15. Rodrigues EB, Meyer $\mathrm{CH}$, Farah ME, Kroll P. Intravitreal staining of the internal limiting membrane using indocyanine green in the treatment of macular holes. Ophthalmologica. 2005;219(5):251-62. Review.

16. Brasil OM, Brasil OF. [Comparative analysis of macular hole surgery followed by internal limiting membrane removal with and without indocyanine green staining]. Arq Bras Oftalmol. 2006;69(2):157-60. Portuguese.

17. Horio N, Horiguchi M. Effect on visual outcome after macular hole surgery when staining the internal limiting membrane with indocyanine green dye. Arch Ophthalmol. 2004;122(7):992-6.

18. Sheidow TG, Blinder KJ, Holekamp N, Joseph D, Shah G, Grand MG, et al. Outcome results in macular hole surgery: an evaluation of internal limiting membrane peeling with and without indocyanine green. Ophthalmology. 2003;110(9):1697-701.

19. Farah ME, Maia M, Rodrigues EB. Dyes in ocular surgery: principles for use in chromovitrectomy. Am J Ophthalmol. 2009;148(3):332-40. Review.

20. Lai MM, Williams GA. Anatomical and visual outcomes of idiopathic macular hole surgery with internal limiting membrane removal using low-concentration indocyanine green. Retina. 2007;27(4):477-82.

21. Engelbrecht NE, Freeman J, Sternberg P Jr, Aaberg TM Sr, Aaberg TM Jr, Martin DF, et al. Retinal pigment epithelial changes after macular hole surgery with indocyanine green-assisted internal limiting membrane peeling. Am J Ophthalmol. 2002;133(1):89-94.

22. Rodrigues EB, Penha FM, Furlani B, Meyer CH, Maia M, Farah ME. Historical aspects and evolution of the application of vital dyes in vitreoretinal surgery and chromovitrectomy. Dev Ophthalmol. 2008;42:29-34.

23. Gandorfer A, Haritoglou C, Kampik A. Ultrastructure of the internal limiting membrane. Ophthalmology. 2004;111(9):1793; author reply 1793-4.

24. Kamura Y, Sato Y, Isomae T, Shimada H. Effects of internal limiting membrane peeling in vitrectomy on diabetic cystoid macular edema patients. Jpn J Ophthalmol. 2005;49(4):297-300.

25. Bardak Y,Cekiç O,Tið SU. Comparison of ICG-assisted ILM peeling and triamcinolone-assisted posterior vitreous removal in diffuse diabetic macular oedema. Eye (Lond). 2006;20(12):1357-9.
26. Radetzky S, Walter P, Fauser S, Koizumi K, Kirchhof B, Joussen AM. Visual outcome of patients with macular edema after pars plana vitrectomy and indocyanine green-assisted peeling of the internal limiting membrane. Graefes Arch Clin Exp Ophthalmol. 2004;242(4):273-8.

27. Lanzetta P,Polito A, Del Borrello M,Narayanan R, Shah VA, Frattolillo A, et al. Idiopathic macular hole surgery with low-concentration infracyanine green-assisted peeling of the internal limiting membrane. Am J Ophthalmol. 2006;142(5):771-6.

28. Rivett K, Kruger L, Radloff S. Infracyanine-assisted internal limiting membrane peeling in macular hole repair: does it make a difference? Graefes Arch Clin Exp Ophthalmol. 2004;242(5):393-6.

29. Kolacny D, Parys-Vanginderdeuren R, Van Lommel A, Stalmans P. Vitrectomy with peeling of the inner limiting membrane for treating diabetic macular edema. Bull Soc Belge Ophtalmol. 2005;(296):1523.

30. Husson-Danan A, Glacet-Bernard A, Soubrane G, Coscas G. Clinical evaluation of the use of indocyanine green for peeling the internal limiting membrane in macular hole surgery. Graefes Arch Clin Exp Ophthalmol. 2006;244(3):291-7.

31. La Heij EC, Dieudonné SC, Mooy CM, Diederen RM, Liem AT, van Suylen RJ, et al. Immunohistochemical analysis of the internal limiting membrane peeled with infracyanine green. Am J Ophthalmol. 2005;140(6):1123-5.

32. Haritoglou C, Gandorfer A, Gass CA, Kampik A. Histology of the vitreoretinal interface after staining of the internal limiting membrane using glucose $5 \%$ diluted indocyanine and infracyanine green. Am J Ophthalmol. 2004;137(2):345-8.

33. Kodjikian L, Richter T, Halberstadt M, Beby F, Flueckiger F, Boehnke $\mathrm{M}$, et al. Toxic effects of indocyanine green, infracyanine green, and trypan blue on the human retinal pigmented epithelium. Graefes Arch Clin Exp Ophthalmol. 2005;243(9):917-25.

34. Enaida H, Hisatomi T, Goto Y, Hata Y, Ueno A, Miura M, et al. Preclinical investigation of internal limiting membrane staining and peeling using intravitreal brilliant blue G. Retina. 2006;26(6):623-30.

35. Enaida H, Hisatomi T, Hata Y, Ueno A, Goto Y, Yamada T, et al. Brilliant blue $\mathrm{G}$ selectively stains the internal limiting membrane/ brilliant blue G-assisted membrane peeling. Retina. 2006;26(6):631-6.

36. Cervera E, Díaz-Llopis M, Salom D, Udaondo P,Amselem L. [Internal limiting membrane staining using intravitreal brilliant blue G: good help for vitreo-retinal surgeon in training]. Arch Soc Esp Oftalmol. 2007;82(2):71-2. Spanish.

37. Shimada H, Nakashizuka H, Hattori T, Mori R, Mizutani Y, Yuzawa M. Double staining with brilliant blue $\mathrm{G}$ and double peeling for epiretinal membranes. Ophthalmology. 2009;116(7):1370-6.

38. Malerbi FK, Maia M, Farah ME, Rodrigues EB. Subretinal brilliant blue $\mathrm{G}$ migration during internal limiting membrane peeling. Br J Ophthalmol. 2009;93(12):1687. Erratum in: Br J Ophthalmol. 2011;95(1):154.

39. Horio N, Horiguchi M, Yamamoto N. Triamcinolone-assisted internal limiting membrane peeling during idiopathic macular hole surgery. Arch Ophthalmol. 2005;123(1):96-9.

40. Kampougeris G, Cheema R, McPherson R, Gorman C. Safety of Triamcinolone acetonide (TA)-assisted pars plana vitrectomy in macular hole surgery. Eye (Lond). 2007;21(5):591-4.

41. Shah GK, Rosenblatt BJ, Blinder KJ, Grand MG, Smith M. Triamcinolone-assisted internal limiting membrane peeling. Retina. 2005;25(8):972-5. 
42. Karacorlu M, Ozdemir H, Arf Karacorlu S. Does intravitreal triamcinolone acetonide-assisted peeling of the internal limiting membrane effect the outcome of macular hole surgery? Graefes Arch Clin Exp Ophthalmol. 2005;243(8):754-7.

43. Maia M, Penha FM, Farah ME, Dib E, Príncipe A, Lima Filho AA, et al. Subretinal injection of preservative-free triamcinolone acetonide and supernatant vehicle in rabbits: an electron microscopy study. Graefes Arch Clin Exp Ophthalmol. 2008;246(3):379-88.

44. Lee KL, Dean S, Guest S. A comparison of outcomes after indocyanine green and trypan blue assisted internal limiting membrane peeling during macular hole surgery. Br J Ophthalmol. 2005;89(4):420-4.

45. Beutel J, Dahmen G, Ziegler A, Hoerauf H. Internal limiting membrane peeling with indocyanine green or trypan blue in macular hole surgery: a randomized trial. Arch Ophthalmol. 2007;125(3):326-32.

46. Haritoglou C, Eibl K, Schaumberger M, Mueller AJ, Priglinger S, Alge $\mathrm{C}$, et al. Functional outcome after trypan blue-assisted vitrectomy for macular pucker: a prospective, randomized, comparative trial. Am J Ophthalmol. 2004;138(1):1-5.

47. Narayanan R, Kenney MC, Kamjoo S, Trinh TH, Seigel GM, Resende GP, et al. Trypan blue: effect on retinal pigment epithelial and neurosensory retinal cells. Invest Ophthalmol Vis Sci. 2005;46(1):304-9.

48. Stalmans P, Feron EJ, Parys-Van Ginderdeuren R, Van Lommel A, Melles GR, Veckeneer M. Double vital staining using trypan blue and infracyanine green in macular pucker surgery. $\mathrm{Br} \mathrm{J}$ Ophthalmol. 2003;87(6):713-6.

49. Kwok AK, Lai TY, Li WW, Yew DT, Wong VW. Trypan blue- and indocyanine green-assisted epiretinal membrane surgery: clinical and histopathological studies. Eye (Lond). 2004;18(9):882-8.

50. Uno F, Malerbi F, Maia M, Farah ME, Maia A, Magalhães O Jr. Subretinal trypan blue migration during epiretinal membrane peeling. Retina. 2006;26(2):237-9.

51. Balayre S, Boissonnot M,Fernandez B, Quellard N, Babin P, Dighiero P. [Ultrastructural study of epiretinal membrane stained by trypan blue: 15 case reports]. J Fr Ophtalmol. 2005;28(2):159-67. French.

52. Balayre S, Boissonnot M,Paquereau J,Dighiero P. [Evaluation of trypan blue toxicity in idiopathic epiretinal membrane surgery with macular function test using multifocal electroretinography: seven prospective case studies]. J Fr Ophtalmol. 2005;28(2):169-76. French.

53. Lesnik Oberstein SY, Mura M, Tan SH, de Smet MD. Heavy trypan blue staining of epiretinal membranes: an alternative to infracyanine green. Br J Ophthalmol. 2007;91(7):955-7.

54. Marmor MF. Retinal detachment from hyperosmotic intravitreal injection. Invest Ophthalmol Vis Sci. 1979;18(12):1237-44.

55. Negi A, Marmor MF. Effects of subretinal and systemic osmolality on the rate of subretinal fluid resorption. Invest Ophthalmol Vis Sci. 1984;25(5):616-20.

56. Mennel S, Meyer CH, Tietjen A, Rodrigues EB, Schmidt JC. Patent blue: a novel vital dye in vitreoretinal surgery. Ophthalmologica. 2006;220(3):190-3.

57. Lüke C, Lüke M, Sickel W, Schneider T. Effects of patent blue on human retinal function. Graefes Arch Clin Exp Ophthalmol. 2006;244(9):1188-90.

58. Haritoglou C, Yu A, Freyer W, Priglinger SG, Alge C, Eibl K, et al. An evaluation of novel vital dyes for intraocular surgery. Invest Ophthalmol Vis Sci. 2005;46(9):3315-22.

59. Haritoglou C, Schumann RG, Strauss R, Priglinger SG, Neubauer AS, Kampik A. Vitreoretinal surgery using bromphenol blue as a vital stain: evaluation of staining characteristics in humans. Br J Ophthalmol. 2007;91(9):1125-8
60. Haritoglou C, Strauss R, Priglinger SG, Kreutzer T, Kampik A. Delineation of the vitreous and posterior hyaloid using bromophenol blue. Retina. 2008;28(2):333-9.

61. Hillenkamp J, Saikia P, Herrmann WA, Framme C, Gabel VP, Sachs HG. Surgical removal of idiopathic epiretinal membrane with or without the assistance of indocyanine green: a randomised controlled clinical trial. Graefes Arch Clin Exp Ophthalmol. 2007;245(7):973-9.

62. Foster RE, Petersen MR, Da Mata AP, Burk SE, Rosa RH Jr, Riemann $\mathrm{CD}$. Negative indocyanine green staining of epiretinal membranes. Retina. 2002;22(1):106-8.

63. Sakamoto H, Yamanaka I, Kubota T, Ishibashi T. Indocyanine greenassisted peeling of the epiretinal membrane in proliferative vitreoretinopathy. Graefes Arch Clin Exp Ophthalmol. 2003;241(3):204-7.

64. Carpentier C,Zanolli M,Wu L, Sepulveda G, Berrocal MH, Saravia M, et al. Residual internal limiting membrane after epiretinal membrane peeling: Results of the Pan-American Collaborative Retina Study Group. Retina. 2013;33(10):2026-31.

65. Jackson TL, Kwan AS, Laidlaw AH, Aylward W. Identification of retinal breaks using subretinal trypan blue injection. Ophthalmology. 2007;114(3):587-90

66. Salicone A, Smiddy WE, Venkatraman A, Feuer W. Management of retinal detachment when no break is found. Ophthalmology. 2006;113(3):398-403.

67. Bonanomi MT, Nicoletti AG, Carricondo PC, Buzalaf F, Kara-José N $\mathrm{Jr}$, Gomes AM, et al. Retinal thickness assessed by optical coherence tomography (OCT) in pseudophakic macular edema. Arq Bras Oftalmol. 2006;69(4):539-44.

68. Ferraz DA, Morita C, Pretti RC, Nascimento VP, Maia Junior OO, Barros AC, et al. [Use of intravitreal bevacizumab or triamcinolone acetonide as a preoperative adjunct to vitrectomy for vitreous haemorrhage in diabetics]. Rev Bras Oftalmol. 2013;72(1):12-6. Portuguese.

69. Ruiz-Moreno JM, Montero JA, Bayon A, Rueda J, Vidal M. Retinal toxicity of intravitreal triamcinolone acetonide at high doses in the rabbit. Exp Eye Res. 2007;84(2):342-8.

70. Morrison VL, Koh HJ, Cheng L, Bessho K, Davidson MC, Freeman WR. Intravitreal toxicity of the kenalog vehicle (benzyl alcohol) in rabbits. Retina. 2006;26(3):339-44.

71. Das T, Vedantham V. Intravitreal sodium fluorescein enhances visualization of clear vitreous during vitreous surgery for macular hole: a safety and efficacy study. Clin Experiment Ophthalmol.2004;32(1):557.

72. Guo S, Tutela AC, Wagner R, Caputo AR. A comparison of the effectiveness of four biostains in enhancing visualization of the vitreous. $\mathrm{J}$ Pediatr Ophthalmol Strabismus. 2006;43(5):281-4.

73. Hata Y, Enaida H, Sassa Y, Ueno A, Miura M, Hisatomi T, et al. Preclinical investigation of fluorometholone acetate as a potential new adjuvant during vitreous surgery. Graefes Arch Clin Exp Ophthalmol. 2007;245(7):1019-25.

74. Verma L, Prakash G, Tewari HK. Trypan blue enhanced vitrectomy in clear gel vitrectomy. Indian J Ophthalmol. 2003;51(1):106.

75. Czajka MP, McCuen BW 2nd, Cummings TJ, Nguyen H, Stinnett S, Wong F. Effects of indocyanine green on the retina and retinal pigment epithelium in a porcine model of retinal hole. Retina. 2004;24(2):275-82.

76. Schmidt JC, Rodrigues EB, Meyer CH, Hoerle S, Kroll P. A modified technique to stain the internal limiting membrane with indocyanine green. Ophthalmologica. 2004;218(3):176-9. 
77. Meyer CH, Rodrigues EB. A novel applicator for the selective painting of pre-retinal structures during vitreoretinal surgery. Graefes Arch Clin Exp Ophthalmol. 2005;243(5):487-9.

78. Rizzo S, Belting C, Genovesi-Ebert F, Vento A, Cresti F. Modified technique for safer indocyanine-green-assisted peeling of the internal limiting membrane during vitrectomy for macular hole repair. Graefes Arch Clin Exp Ophthalmol. 2006;244(12):1615-9.

79. Cacciatori M, Azzolini M, Sborgia M, Coppola M, De Molfetta V. Sodium hyaluronate $2.3 \%$ prevents contact between indocyanine green and retinal pigment epithelium during vitrectomy for highly myopic macular hole retinal detachment. Retina. 2004;24(1):160-1.

80. Costa Ede P, Rodrigues EB, Farah ME, Dib E, Penha F, Magalhães O $\mathrm{Jr}$, et al. Vital dyes and light sources for chromovitrectomy: comparative assessment of osmolarity, $\mathrm{pH}$, and spectrophotometry. Invest Ophthalmol Vis Sci. 2009;50(1):385-91.

81. Rodrigues EB, Meyer CH, Mennel S, Farah ME. Mechanisms of intravitreal toxicity of indocyanine green dye: implications for chromovitrectomy. Retina. 2007;27(7):958-70. Review.

82. Haritoglou C, Priglinger S, Gandorfer A, Welge-Lussen U, Kampik A. Histology of the vitreoretinal interface after indocyanine green staining of the ILM, with illumination using a halogen and xenon light source. Invest Ophthalmol Vis Sci. 2005;46(4):1468-72.
83. Trevithick-Sutton CC, Foote CS, Collins M, Trevithick JR. The retinal carotenoids zeaxanthin and lutein scavenge superoxide and hydroxyl radicals: achemiluminescence and ESR study. Mol Vis. 2006;12:1127-35.

84. Junghans A, Sies H, Stahl W. Macular pigments lutein and zeaxanthin as blue light filters studied in liposomes. Arch Biochem Biophys. 2001;391(2):160-4.

85. Stahl W. Macular carotenoids: lutein and zeaxanthin. Dev Ophthalmol. 2005;38:70-88. Review.

86. Kijlstra A,Tian Y,Kelly ER, Berendschot TT. Lutein: more than just a filter for blue light. Prog Retin Eye Res. 2012;31(4):303-15. Review.

87. Chen J,Ferreira MA, Farah ME, de Carvalho AM, Alves Ferreira RE, de Moraes Filho MN, et al. Posterior hyaloid detachment and internal limiting membrane peeling assisted by anthocyanins from acai fruit (Euterpe oleracea) and 10 other natural vital dyes: experimental study in cadaveric eyes. Retina. 2013;33(1):89-96.

\section{Corresponding author}

Rafael Ramos Caiado

Av. Higienópolis, $\mathrm{n}^{\circ} 870$ - Higienópolis

CEP 01238-000 - São Paulo (SP), Brasil

E-mail: rrcaiado@hotmail.com 